\title{
Proposed framework for the CALABARZON destination competitiveness
}

\author{
Ricafort, Marivic V. $\triangle$ \\ Lyceum of the Philippines University - Batangas, Philippines (mvricafort@lpubatangas.edu.ph)
}

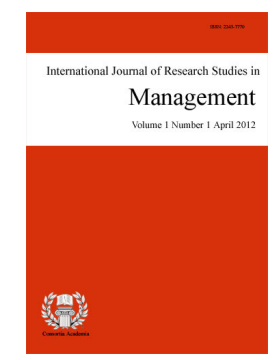

ISSN: $2243-7770$ Online ISSN: 2243-7789

OPEN ACCESS

\section{Abstract}

This study assessed the competitiveness, attractiveness, and image management of the tourist destination in CALABARZON. Specifically, the study tested the significant relationship among variables as given competitiveness, attractiveness and image management. Finally, framework on tourism innovation in CALABARZON was proposed. The study used quantitative descriptive research method to 385 tourists who visited CALABARZON region. Based on the result of the study, there is a high level of competitiveness in the core resources and attractors, supporting factors and resources and qualifying and amplifying determinants. Also, it was found out that there was a significant positive relationship across competitiveness, attractiveness, and image management. A framework was proposed for the CALABARZON Destination Competitiveness. It is recommended for Department of Tourism to provide recognition to the province or municipality that contributes to tourism development and preservation to motivate all tourism officer and local government unit to participate in ensuring destination competitiveness to all the provinces.

Keywords: tourist destination; competitiveness; attractiveness; image management 


\section{Proposed framework for the CALABARZON destination competitiveness}

\section{Introduction}

Tourism is an important industry in the Philippines because it provides a direct source of income to the country. It is highly favorable because it brings in employment, income, and foreign exchange. Tourists may perceive all characteristics of a destination and therefore effectively measure its competitiveness in the industry. Thus, to some extent it will provide a better source of idea of how far a destination does would go in the aspect of its competitiveness, attractiveness, and image management. Tourism has become an important sector that has an impact on development of country economy, and it has been considered as the backbone in the financial hubs many countries in the world (Khan et al., 2020). Being one of the fastest growing industry, innovation is an important factor in tourism development. For the tourism sector to innovate it is crucial for a destination to maintain its competitiveness, attractiveness and build up the image perceived by both local and the tourists.

Competitiveness is the desire to sustain an organization's competitive role by pleasant perceptions of consumers and shareholders at the same time as continuously holding off risks and taking advantage of the opportunities in the competitive climate. Therefore, by persevering with the growth of the organization's services and expertise, competitiveness can better be sustained (Tassawa \& Banjongprasert, 2019). The importance of the image of a tourist destination is commonly recalled because it determines the subjective interpretation, consequent actions, and destination preference of a person. Instead of facts, images are more important than physical tools and expectations are what drive clients to act or not to act. Although this may be a very large argument, we are of the opinion that since the person has not been to the location before, his information and experience about the destination is likely to be backed only by secondary sources.

CALABARZON as a tourism destination is attractive and competitive, it has a lot of strengths and a fair share of weaknesses, but its effort is still not enough to be consistently considered as a travel destination. Truly indeed, CALABARZON is a beautiful tourist destination but why it is not the best/first choice of many tourists. Perhaps one of the most critical factors in forming a popular tourist destination is the visual appearance of a location, as visitors would judge a destination in a matter of seconds upon arrival.

The researcher as a tourism educator is motivated to conduct a rational study on tourism competitiveness, attractiveness and image management that influence the decision making of the tourist visiting a tourist destination. The researcher is interested in examining tourist who experience visiting attractions in CALABARZON and to understand the influencing factors of their visit. It is hoped that the conduct of this study would be of benefit to operators of tourist destinations as a basis for advancing the efficiency of the services and facilities offered and thereby increasing tourist's probability of visiting the destination in the CALABARZON area. It is also hoped to provide to the theoretical understanding of the tourism in the entire CALABARZON and to contribute the formulation, growth and development of strategies for the innovation the tourism destination in the region.

\section{Methodology}

\subsection{Research design}

The study used quantitative descriptive research method in gathering data, describing the essential components or variables to establish the relevant evidence and to validate the tourist destination competitiveness, attractiveness, and image management of CALABARZON Region. Moreover, the researcher made use of a triangulation using an online survey form, observation and interview to some of the respondents which help in enriching the discussion and analysis of the result of the study. Descriptive method of research will describe each 
factor analysis and will be used to determine, describe, or identify what is (Dudovskiy, 2016).

\subsection{Participants of the study}

The respondents of the study were the tourists who visited the famous tourist destinations in CALABARZON and the host/local community/officials of the municipality/tourism officers. The researcher emailed Batangas' Provincial Tourism Office to have a copy of CALABARZON 2018 Tourism Situational Report from Department of Tourism IV-A Regional Office. Appendix A contains the copy of certification of the said data. Selected tourists who are visiting the tourist destination answered the questionnaire. There was a total sample of 385 respondents who answered the questionnaire. The number of respondents was computed based on the number of tourist arrival of 2018 based on the documents gathered from DOT Region IV-A: CALABARZON using Raosoft in addition the respondents was randomly allocated per tourist destinations in CALABARZON.

The researcher made use of a Stratified Random Sampling. The researcher would like to ensure that groups of interest or subsections of the population considered important for the study are adequately represented. For this study, a statistician advised an equal and reasonably precise estimate for each province of the total population.

\subsection{Instrument of the study}

The instrument used was an adapted questionnaire from a previous study with Cronbach Alpha Result. The researcher made modification to tailor fit based on the present time. The survey instrument consists of four (3) sections.

Part I assess the competitiveness of the tourist destination in CALABARZON in terms of: core resources and attractors, supporting factors and resources and qualifying and amplifying determinants measuring using Ritchie and Crouch (2010); Ylagan (2018) model for assessing the destinations' competitiveness. It has undergone a reliability test and got a score of .918 , this implied significantly valid and reliable results.

Part II determine the factors influencing the attractiveness in term of key attributes, facilities and services, infrastructures and miscellaneous. The value of Cronbach's Alpha of the questionnaire came out to be 0.77 , which may be considered as reliable. Tested from the study Factors influencing the attractiveness of a tourist destination: A case study authored by Das, Mohapatra, Sharma, and Sarkar (2007) and Measuring the Resort Business Competitiveness in Batangas Province (2018).

Part III determine the image management of the tourist destination in terms of leisure and tourist amenities, shopping and food paradise, local residents and nightlife, political stability, adventure and weather, local culture, cleanliness and personal safety and convenience. The instrument from the study Singapore's Image as a Tourist Destination by Hui and Wan (2003) items has been grouped into factors measured using Cronbach's alpha tests. The results are as follows leisure and tourist amenities (.83); shopping and food paradise (.80); local residents and nightlife (.83); political stability (.77); adventure and weather (.52); local culture (.86); cleanliness (.65) and personal safety and convenience (.50).

\subsection{Data gathering procedure and Analysis}

Upon the approval of the Panelist and Program Dean, the researcher created a google form which was sent through social media and with the help of the organizations like Philippine Association of Researchers for Tourism and Hospitality (PARTH), Tourism Educators and Movers of the Philippines (TEAM Philippines), Network of Professionals Researchers and Educators (NPRE) in administering and answering the online survey and the researcher administered the distribution of questionnaire to the target respondents. The data gathered from five famous provinces in Region IV-A: CALABARZON based on the tourist arrival of year 2018 
Ricafort, M. V.

documented by DOT Region IV-A. After the collection of data, it was tallied, encoded and analyzed using different statistical tools such as frequency distribution, weighted mean, and independent sample $t$-test and analysis of variance (ANOVA) and Pearson-r. This study used different statistical tools such independent sample $t$-test and analysis of variance (ANOVA) and Pearson- $r$. The answers are determined by obtaining the general average as shown by the weighted mean, while the distribution of frequency is a measure of a certain portion of the total number of visitors. The data was analyzed using Statistical Package for Social Sciences (SPSS).

\subsection{Ethical consideration}

The researcher prioritized and assured the welfare of the participants. Prior to the study, full approval was received from the participants. All gathered data were treated with utmost confidentially. The results were utilized for academic purposes only. In compliance to Data Privacy Act of 2012 and to ensure full confidentiality, the research provided consent form before the respondents accomplished the survey questionnaire voluntarily and no personal opinion were solicited, while all the results were treated and analyzed with full protection and confidentiality.

\section{Result and discussion}

Table 1

Summary of competitiveness, attractiveness and image management

\begin{tabular}{|c|c|c|c|}
\hline Variables/Items & $\mathrm{CM}$ & VI & Rank \\
\hline \multicolumn{4}{|c|}{ Competitiveness: Core resources and attractors } \\
\hline Physiography and Climate & 3.44 & Much Competitive & 2 \\
\hline Culture and History & 3.38 & Much Competitive & 3 \\
\hline Mix of Activities & 3.46 & Much Competitive & 1 \\
\hline Special Events & 3.15 & Much Competitive & 4 \\
\hline Cluster Mean & 3.43 & Much Competitive & \\
\hline \multicolumn{4}{|c|}{ Competitiveness: Supporting factors \& resources } \\
\hline Infrastructure & 3.14 & Much Competitive & 3 \\
\hline Facilitating Resources & 3.31 & Much Competitive & 2 \\
\hline Spirit of Hospitality & 3.49 & Much Competitive & 1 \\
\hline Cluster Mean & 3.31 & Much Competitive & \\
\hline \multicolumn{4}{|c|}{ Competitiveness: Qualifying and Amplifying Determinants } \\
\hline Safety and Security & 3.27 & Much Competitive & 3 \\
\hline Awareness and Image & 3.41 & Much Competitive & 1 \\
\hline Cost / Value & 3.28 & Much Competitive & 2 \\
\hline Cluster Mean & 3.32 & Much Competitive & \\
\hline \multicolumn{4}{|c|}{ Factors influencing the attractiveness } \\
\hline Key Attributes & 3.40 & Much Attractive & 2 \\
\hline Facilities \& Services & 3.47 & Much Attractive & 1 \\
\hline Cluster Mean & 3.44 & Much Attractive & \\
\hline \multicolumn{4}{|c|}{ Image management of the tourist destination } \\
\hline leisure and tourist amenities & 3.45 & Agree & 3.5 \\
\hline shopping and food paradise & 3.22 & Agree & 8 \\
\hline local residents and nightlife & 3.44 & Agree & 5.5 \\
\hline political stability & 3.32 & Agree & 7 \\
\hline adventure \& weather & 3.46 & Agree & 2 \\
\hline local culture & 3.45 & Agree & 3.5 \\
\hline Cleanliness & 3.44 & Agree & 5.5 \\
\hline personal safety \& convenience & 3.49 & Agree & 1 \\
\hline Cluster Mean & 3.41 & Agree & \\
\hline
\end{tabular}

Table 1 presents the summary table of Competitiveness, Attractiveness and Image Management in 
CALABARZON Tourist Destination. For destination competitiveness, the result shows that among the items under core resources and attractors it is mix of activities (3.46) that rank first while special event (3.15) ranked last. Result also shows that among the items under supporting factors and resources it is spirit of hospitality (3.49) that rank first while Infrastructure (3.14) ranked last. Moreover, the result shows that among the items under qualifying and amplifying determinants it is awareness and image (3.41) that rank first while safety and security (3.27) ranked last. Mix of activities, spirit of hospitality and awareness and image is essential for destination competitiveness as perceived by the respondents as it ranks first.

Given this fact, a destination shall be visited by tourist mainly because of the activities offered by the tourism enterprise, with the hospitable locals and tourism staff that will make the tourist feel welcome and at home and most importantly, the awareness and image of the destination will greatly affect to the destination competitiveness as it gives positive insight for the tourist. With the use of social media and word of mouth these images can boost and uplift the awareness among the tourist on local and in international. As stated on the study made by Rey-Maquieira (2016) classical definition of destination competitiveness is understood on the basis of "its ability to increase tourism expenditure to increasingly attract visitors while providing them with satisfying, memorable experiences, and to do so in a profitable way, while enhancing the wellbeing of destination residents and preserving the natural capital of the destination for future generations." and as stated in the study of Koo (2016) the concept of destination competitiveness, measures the ability to provide higher quality travel experiences to the visitors than other destinations.

Destination managers must also decide whether to continue consolidating their experiences and markets or innovate while preparing their tourism destination growth by designing new experiences and addressing new markets. While these approaches are not mutually exclusive, it is critical for destination competition to follow a strategic approach to determining which interactions can be signature tourist drawcards featuring in the brand profile and marketing of the destination, and which markets to target their marketing efforts on. A restructuring strategy is adopted by most destination managers because this is also the most successful, easiest and least divisive solution. The solution is to innovate by designing unique activities and attracting new tourist audiences to increase the popularity of the destination (Gardiner, 2018).

With regards to factors influencing the attractiveness, it is evident that facilities and services (3.47) rank first while the key attributes (3.40) rank last. A tourist destination could be attractive given the fact that it offers variety of facility and services for the reason that tourist desires to experience all these facilities and services that the destination has to offer. It is important for the destination to not just be providing attractive tourist spots moreover; the destination shall be attractive whenever all the facilities and services are available for the tourist to enjoy. It is possible to recognize beauty as one of the most significant variables in the growth of tourism. The destination image draws tourists to pay a visit. The single and most significant explanation why visitors come to the destination is because the visitor needs to enjoy attractions that the location has to give in recreational tourism. Moreover, a common trait of tourist attractions is that they are shared with the host group. It is possible to separate tourist attractions into nature attractions, cultural attractions and people-developed attractions such as tour planning (Fletcher et al., 2017).

For the image management of the tourist destination, among the items enumerated personal safety and convenience (3.49) ranks first while shopping and food paradise (3.22) ranks last. The respondents affirm that it is their safety and convenience that they are prioritizing and for them it is important for the tourism destination. Who would prefer to go to destination that your safety is at risk? Rest assured that a tourist would be satisfied and motivated to visit a place that is secured; thus, CALABARZON region is a destination that safety and convenience is on top priority. Hultman et al. (2015) argue that the image of the destination encourages tour satisfaction, favorable satisfaction with the tour, favorable word-of - mouth, reputation and desire to visit the tourist destination. Tourist satisfaction contributes to the recognition of destinations and ultimately facilitates favorable word-of - mouth, while destination identification promotes positive / negative world-of-mouth and the choice to visit the destination. Wu (2016) agrees with this assertion that the key variables that contribute to 
Ricafort, M. V.

destination loyalty are the overall destination image, satisfaction and tourist experience. In addition, the image of the destination and the experience of tourists impact the destination's satisfaction.

Table 2

Significant relationship across competitiveness, attractiveness, and image management

\begin{tabular}{|c|c|c|c|c|c|c|}
\hline \multirow[b]{2}{*}{ Variables/Items } & & \multicolumn{3}{|c|}{ Competitiveness } & \multicolumn{2}{|c|}{ Attractiveness } \\
\hline & & $\begin{array}{c}\text { core } \\
\text { resources }\end{array}$ & $\begin{array}{l}\text { Supporting } \\
\text { factors }\end{array}$ & $\begin{array}{c}\text { Qualifying \& } \\
\text { Amplifying }\end{array}$ & $\begin{array}{c}\text { Key } \\
\text { Attributes }\end{array}$ & $\begin{array}{c}\text { Facilities \& } \\
\text { Services }\end{array}$ \\
\hline \multicolumn{7}{|l|}{ Attractiveness } \\
\hline \multirow[t]{2}{*}{ Key Attributes } & $r$-value & $.621(* *)$ & $.603(* *)$ & $.529(* *)$ & 1 & $.586(* *)$ \\
\hline & $p$-value & .000 & .000 & .000 & & .000 \\
\hline \multirow[t]{2}{*}{ Facilities \& Services } & $r$-value & $.732(* *)$ & $.815(* *)$ & $.770(* *)$ & $.586(* *)$ & 1 \\
\hline & $p$-value & .000 & .000 & .000 & .000 & \\
\hline \multicolumn{7}{|l|}{ Image management } \\
\hline \multirow[t]{2}{*}{ leisure and tourist amenities, } & $r$-value & $.640(* *)$ & $.648(* *)$ & $.568(* *)$ & $.527(* *)$ & $.611(* *)$ \\
\hline & $p$-value & .000 & .000 & .000 & .000 & .000 \\
\hline \multirow[t]{2}{*}{ shopping and food paradise } & $r$-value & $.580(* *)$ & $.653(* *)$ & $.471(* *)$ & $.569(* *)$ & $.520(* *)$ \\
\hline & $p$-value & .000 & .000 & .000 & .000 & .000 \\
\hline \multirow[t]{2}{*}{ residents and nightlife } & $r$-value & $.480(* *)$ & $.647(* *)$ & $.551(* *)$ & $.517(* *)$ & $.622(* *)$ \\
\hline & $p$-value & .000 & .000 & .000 & .000 & .000 \\
\hline \multirow[t]{2}{*}{ political stability } & $r$-value & $.507(* *)$ & $.619(* *)$ & $.547(* *)$ & $.528(* *)$ & $.585(* *)$ \\
\hline & $p$-value & .000 & .000 & .000 & .000 & .000 \\
\hline \multirow[t]{2}{*}{ adventure and weather } & $r$-value & $.547(* *)$ & $.575(* *)$ & $.577(* *)$ & $.462(* *)$ & $.625(* *)$ \\
\hline & $p$-value & .000 & .000 & .000 & .000 & .000 \\
\hline \multirow[t]{2}{*}{ local culture } & $r$-value & $.408(* *)$ & $.479(* *)$ & $.489(* *)$ & $.371(* *)$ & $.463(* *)$ \\
\hline & $p$-value & .000 & .000 & .000 & .000 & .000 \\
\hline \multirow[t]{2}{*}{ cleanliness } & $r$-value & $.561(* *)$ & $.614(* *)$ & $.615(* *)$ & $.412(* *)$ & $.559(* *)$ \\
\hline & $p$-value & .000 & .000 & .000 & .000 & .000 \\
\hline \multirow{2}{*}{$\begin{array}{l}\text { personal safety and } \\
\text { convenience }\end{array}$} & $r$-value & $.554(* *)$ & $.689(* *)$ & $.643(* *)$ & $.407(* *)$ & $.616(* *)$ \\
\hline & $p$-value & .000 & .000 & .000 & .000 & .000 \\
\hline
\end{tabular}

Note. ${ }^{* *}$ Correlation is significant at the .01 level (2-tailed).

Table 2 reveals significant positive relationship across competitiveness, attractiveness, and image management as denoted by the computed p-values which are less than .05 alpha level. This signifies that those respondents with high level of assessment on the competitiveness of the tourist destination in CALABARZON are also those respondents with high level of response on attractiveness and image management. This is as same in the study of Zakaria (2018) which shows that there is a relationship between perceived attitudes and the attitude-behaviour relation on destination competitiveness as to the tourist attitudes towards the destination. In addition, Novais et al. (2018) provide three distinct and hierarchically related conceptions of destination competitiveness: the perception of destination competitiveness as a destination, the competitiveness of destinations as quality, and the competitiveness of destinations as a long-term process. Including the interaction between competition and attractiveness, and the complex existence of the competitor collection, aspects of destination competitiveness are addressed.

Since there is a high level of response on attractiveness and management, that only prove that the destination competitiveness may depend on how the local and the tourist may perceive the tourist destination's attractiveness and its image pertaining to how it was thoroughly manage and able to preserve the beauty of its tourism product and services. Furthermore, Miličević et al. (2017) believe that although the destination brand is partly integrated into the two most popular theoretical models of competition in destinations, there is still a need to consider the role of destination branding in achieving competitiveness in destinations. The findings indicate that a well-implemented method of destination branding improves the attractiveness of destinations. 


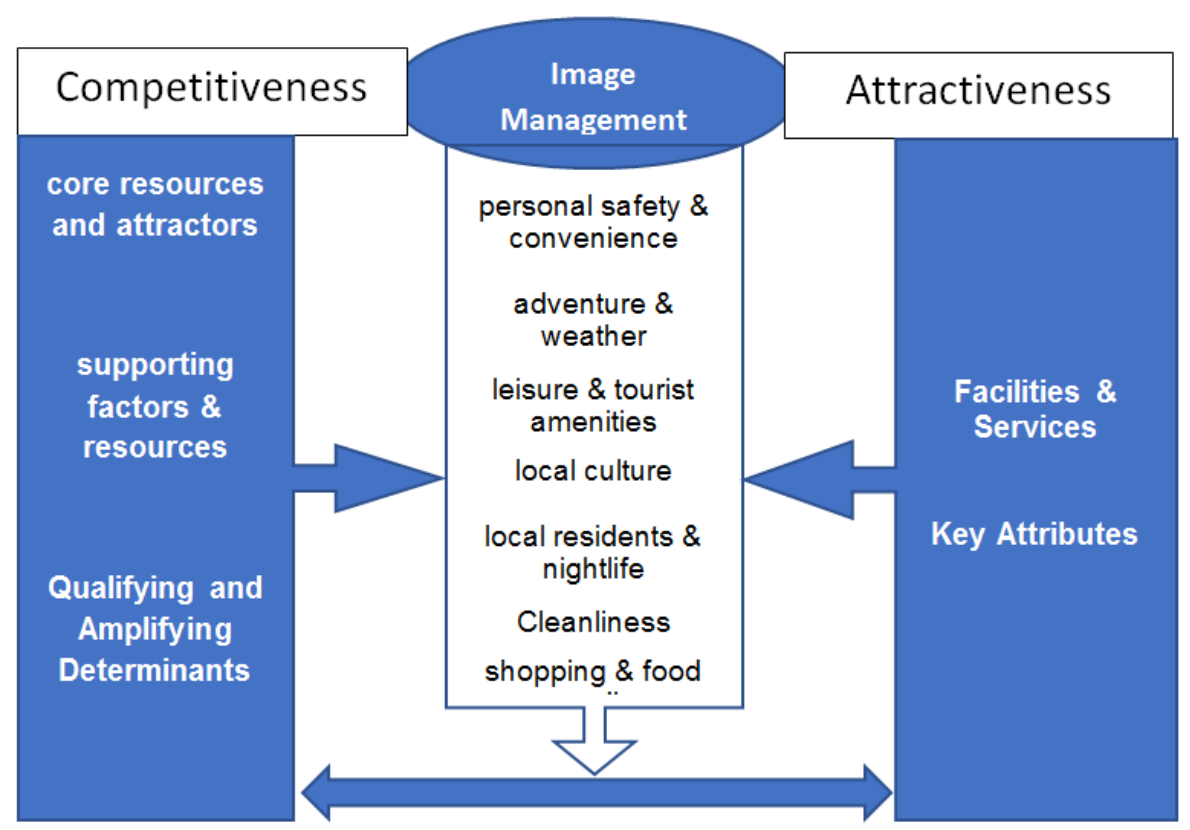

Figure 1. Proposed framework.

In terms of Destination Competitiveness, Ritchie and Crouch have developed a conceptual model focus on determinants that can measure tourist destination competitiveness. The key determinants were identified such as: core resources and key attractors; supporting factors and resources, qualifying and amplifying determinants, tourism policy, planning and development; and destination management. Each determinant has sub-attributes. These determinants and sub-attributes were drawn pressing down to achieve better understanding the relative importance of the tourist destination competitiveness (Ylagan, 2018). Destination Management Companies must also decide whether to continue to integrate their experiences and markets or innovate while preparing their tourism destination growth by designing new experiences and reaching new markets.

Attractiveness, on the other hand, can be considered as one of the most significant factors in the growth of tourism. The destination and its pictures draw tourists to pay a visit. The single and most significant explanation why visitors come to the destination is because the visitor needs to enjoy attractions that the location has to give in recreational tourism. Moreover, a common trait of tourist attractions is that they are shared with the host group. The attractiveness of the destination is an indicator of the attractiveness of the territory in relation to the decision-making process of its visitors. It plays a crucial role in deciding the comparative benefit of the destination; it therefore affects the economic impact of the consumption of products and services in its jurisdiction (Pompurova \& Simockova, 2014). More significantly, a travel destination's attractiveness is literally the potential of a region to draw and accommodate prospective visitors.

The combined effect of destination characteristics and effective image management on the overall attractiveness any tourist destination and considering how it affects the behavior of tourist to visit the place where studied, revealing that service honesty and recreation excitements contributes to the perceived overall destination image both from the previous visitors and non-visitors (Papadimitriou et al., 2015). In addition, the picture of the destination encourages tour satisfaction, favorable tour satisfaction, and favorable word-of-mouth, identity of the tourist destination and purpose to return. Tourist satisfaction contributes to the recognition of destinations and ultimately facilitates positive word-of-mouth, while destination identification promotes positive/negative world-of-mouth and the choice to visit the destination (Hultman, 2015).

\section{Conclusion}

There is a high level of competitiveness in the core resources and attractors, supporting factors and 
resources and qualifying and amplifying determinants. Facilities and services as well as the destination's key attributes are viewed by the respondent as much attractive tourist destination. Respondents positively agree with regards to Image management of the tourist destination in CALABARZON Region. Significant positive relationship across competitiveness, attractiveness, and image management. A framework was proposed for the CALABARZON Destination Competitiveness.

Based on the result of the study, the research recommends for the Department of Tourism may provide recognition to the province or municipality that contributes to tourism development and preservation to motivate all tourism officer and local government unit to participate in ensuring destination competitiveness to all the provinces. Each tourism establishment may boost promotion through social media and digital platform to create awareness and build good image among the region's tourism product and services. Future researchers may conduct similar study using the same instrument to other neighboring region, in order to create tourism competitiveness among the Destination in the Philippines.

\section{References}

Dudovskiy, J. (2016). Descriptive research. http://research-methodology.net

Fletcher, J., Fyall, A., Gilbert, D., \& Wanhill, S. (2017). Tourism: Principles and practice. Pearson.

Gardiner, S., \& Scott, N. (2018). Destination innovation matrix: A framework for new tourism experience and market development. Journal of Destination Marketing \& Management, 10, 122-131. https://doi.org/10.1016/j.jdmm.2018.07.002

Hultman, M., Skarmeas, D., Oghazi, P., \& Beheshti, H. M. (2015). Achieving tourist loyalty through destination personality, satisfaction, and identification. Journal of Business Research, 68(11), 2227-2231. https://doi.org/10.1016/j.jbusres.2015.06.002

Khan, A., Bibi, S., Lorenzo, A., Lyu, J., \& Babar, Z. U. (2020). Tourism and development in developing economies: A policy implication perspective. Sustainability, 12(4), 1618. https://doi.org/10.3390/su12041618

Koo, C., Shin, S., Gretzel, U., Hunter, W. C., \& Chung, N. (2016). Conceptualization of smart tourism destination competitiveness. Asia Pacific Journal of Information Systems, 26(4), 561-576. https://doi.org/10.14329/apjis.2016.26.4.561

Miličević, K., Mihalič, T., \& Sever, I. (2017). An investigation of the relationship between destination branding and destination competitiveness. Journal of Travel \& Tourism Marketing, 34(2), 209-221. https://doi.org/10.1080/10548408.2016.1156611

Novais, M. A., Ruhanen, L., \& Arcodia, C. (2018). Destination competitiveness: A phenomenographic study. Tourism Management, 64, 324-334. https://doi.org/10.1016/j.tourman.2017.08.014

Papadimitriou, D., Apostolopoulou, A., \& Kaplanidou, K. (2015). Destination personality, affective image, and behavioral intentions in domestic urban tourism. Journal of Travel Research, 54(3), 302-315. https://doi.org/10.1177/0047287513516389

Pompurova, K., \& Simockova, I. (2014). Destination attractiveness of Slovakia: perspectives of demand from major tourism source markets. E+M Ekonomie a Management, 17(3). https://doi.org/10.15240/tul/001/2014-3-006

Rey-Maquieira J., \& Ramos, V. (2016). Destination competitiveness. In J. Jafari and H. Xiao (Eds.), Encyclopedia of tourism. Springer. https://doi.org/10.1007/978-3-319-01384-8 54

Tassawa, C., \& Banjongprasert, J. (2019). The effects of destination competitiveness and tourist trust on destination advocacy: The case of international tourists. Veridian E-Journal, 12(5), 203-228.

Wu, C. W. (2016). Destination loyalty modeling of the global tourism. Journal of Business Research, 69(6), 2213-2219. https://doi.org/10.1016/j.jbusres.2015.12.032

Ylagan, M. A. C. (2018). Measuring the resort business competitiveness in Batangas Province.

Zakaria, H. B. M. (2018). Relationship between destination attractiveness and decision to visit Kuala Selangor, Malaysia. 